\title{
Financial Efficiency and the Lucas Puzzle
}

\author{
Amir Goren \\ University of California-Irvine
}

I present a model that provides a theoretical solution to the Lucas Puzzle using Financial Efficiency, which is a matching probability between borrowers and lenders and that may differ between countries. Savers receive only probability-adjusted returns and producers obtain only probability-adjusted capital to produce with.

I address the contention between Rodrik and Subramanian (2009) and financial globalization advocates such as Henry (2007). My model predicts that a financially underdeveloped economy is to benefit from financial integration through FDI capital inflow only if it experiences faster technological growth, or faster Financial Development than the developed economy.

Fitting the model to the data of India, I estimate the temporal evolution of Financial Efficiency and find a sharp increase in India's Financial Efficiency since 1990, which provides a natural experiment for the theoretical prediction above and its congruence with the empirical part of the model. Increases in India's capital per worker and Foreign Direct Investment capital inflow during the same period serve as external validation of the model.

Keywords: capital flow, development, growth, matching, friction

\section{INTRODUCTION}

"Why doesn't capital flow from rich to poor countries?" (Lucas 1990). Since poor countries have lower capital per capita than rich countries, they should have higher marginal product of capital than rich countries, hence, capital should flow from rich to poor countries in search of higher returns but in fact, it does not. I introduce a DSGE model with financial frictions between borrowers and lenders that offers a solution to the Lucas Puzzle. I model Financial Efficiency as a matching probability between borrowers and lenders, which may differ between countries based on attributes such as history, culture, rule of law, regulatory efficiency and trust in institutions as discussed by Reinhart and Rogoff (2004) and Levine (2005). A successful match between a borrower and a lender is not certain and occurs only in probability. As a result, savers receive only probability-adjusted returns and producers obtain only probability-adjusted capital to produce with. The advantage of this modeling choice is that it unifies theory and empirics since it allows the estimation of Financial Efficiency based on macroeconomic data. Financial Efficiency can also represent the fraction of reproducible capital out of total capital as well as the relative cost of capital to output as in Caselli and Feyrer (2007). In line with their empirical findings, Financial Efficiency equalizes the adjusted marginal product of capital between countries in the model. I consider an increase in Financial 
Efficiency to be synonymous to Financial Development as discussed by Goldsmith (1969), King and Levine (1993), Levine and Zervos (1998) and Levine (2005).

This paper makes six contributions: (1) It provides a theoretical solution to the Lucas Puzzle. (2) It estimates the temporal evolution of Financial Efficiency in India. (3) It addresses the contention between Rodrik and Subramanian (2009) and financial globalization advocates such as Henry (2007) by providing conditions for when financial integration is beneficial for the underdeveloped economy. (4) Easterly and Levine (2001) find that "something else" besides capital accumulation is critical for understanding differences in economic growth and income across countries. They find, however, that empirical work does not yet decisively distinguish among the different theoretical conceptions of TFP growth. This paper addresses this lack by distinguishing between two components of TFP growth, the first is labor augmenting technology growth and the second is capital augmenting Financial Development. (5) Smith (2002) notes that "Our understanding of finance and growth will be substantively advanced by the further modeling of the dynamic interactions between the evolution of the financial system and economic growth". In this paper, the evolution of the financial system, or Financial Development, contributes to economic growth in two ways. First, it contributes to TFP directly and immediately. Second, it changes the balanced growth steadystate path of the economy, which over time, leads to growth in stationary capital per capita until a new balanced growth path is reached. (6) Levine (2005) finds that "the empirical proxies for financial development frequently do not measure very accurately the concepts emerging from theoretical models". Further, he states that "future research that more concretely links the concepts from theory with the data will substantively improve our understanding of the finance and growth link." Financial Efficiency in this model unifies the theoretical with the empirical since it is estimated.

Angeletos and Panousi (2011) introduce idiosyncratic entrepreneurial risk into a bilateral trade model, which creates a precautionary motive for saving and a wedge between the interest rate and the marginal product of capital. In their model, the poorer country, dubbed "the South", features a lower interest rate before financial integration. Despite its lower interest rate, the South may also feature a lower capital stock and a lower level of income than the North. This is because the South faces a higher wedge between the marginal product of capital and the interest rate. Financial integration causes interest rates to rise in the South and a decline in the capital stock. This helps solving Gourinchas and Jeanne's "allocation puzzle", which states that capital does not flow more to countries that invest and grow more. However, the long-run effects of financial integration are that the South is able to accumulate more wealth over time. Wealth accumulation through investment in the North is the only path to development, according to their model, despite the initial capital outflow from the South. Gourinchas and Jeanne (2013) augment the neoclassical growth model with two "wedges": one wedge that distorts investment decisions, and one wedge that distorts saving decisions. They find that the investment wedge cannot, by itself, explain the allocation puzzle, and that solving the allocation puzzle requires a saving wedge that is strongly negatively correlated with productivity growth. Mendoza, Quadrini, and Rios-Rull (2009) and Von Hagen and Zhang (2014) analyze the joint determination of financial capital flows and FDI, finding that while financial capital leaves the country where credit market imperfections are more severe (South), FDI flows into it.

This paper focuses on the FDI portion of capital flows since it abstracts from portfolio equity investments. The innovation of this paper is that Financial Efficiency, the complement of financial friction, is both time-varying and a component of Total Factor Productivity. Consequently, there are two sources of TFP growth: technology growth and Financial Development. In addition, the temporal evolution of Financial Efficiency for India is empirically estimated. The previously mentioned papers treat financial frictions as constants and hence, consider TFP growth to be driven exclusively by technological improvement. Neglecting to account for Financial Development as a component of TFP growth might lead to spurious correlations between technology growth and capital flows.

Rodrik and Subramanian (2009) critique Henry's (2007) argument in favor of financial globalization due to its underlying assumption that developing countries are savings-constrained. In contrast, they argue that developing economies could be investment constrained and that the effect of financial integration is often to aggravate investment constraint. The model of this paper predicts that a financially underdeveloped 
economy is to benefit from financial integration through FDI capital inflow, only if it experiences faster technological growth, or faster Financial Development than the developed economy.

The rest of the paper is organized as follows: the second section presents the model, the third section analyzes the model of a closed economy. In the fourth section I analyze the Lucas Puzzle using a financially integrated version of the model. In the fifth section, I fit the model to the data of India and estimate the temporal evolution of Financial Efficiency. In the sixth section I conclude.

\section{MODEL}

\section{Households}

A homogenous continuum of agents of measure 1 provide labor and lend capital to firms. Agents maximize an expected lifetime utility subject to a budget constraint:

$$
\max E_{t} \sum_{j=0}^{\infty} \beta_{j} u\left(c_{t+j}\right)
$$

where $c_{t}$ is consumption, $\beta$ a discount factor and where the period utility is:

$$
u\left(c_{t}\right)=\ln c_{t}
$$

and the agents' budget constraint is:

$$
a_{t+1}=\left(1+p_{t} r_{t}\right) a_{t}+w_{t}-c_{t}
$$

where $a_{t}$ is assets or accumulated savings, $r_{t}$ marginal product of capital, $w_{t}$ the wage and $p_{t}$ is a matching probability between agents and firms, which represents the Financial Efficiency of the economy. Agents that are not matched with a firm $\left(1-p_{t}\right)$ use a storage technology that allows them to bring their assets to the next period with no return on assets. Agents are part of a large household that distributes income equally, which keeps the budget constraint homogenous. I assume away depreciation.

Agents make a take-it or leave-it offers to the firms and hence receive all the surplus from a match. The model is robust to any other bargaining solution provided that the firms distribute their profits to the agents.

\section{Firms}

A continuum of firms of measure 1 that are born and destroyed in each period are used only if they obtain capital through a match with an agent. The aggregate production function is:

$$
Y_{t}=K_{t}^{\alpha}\left(x_{t} L_{t}\right)^{1-\alpha}
$$

where $Y_{t}$ is output, $K_{t}$ capital, $x_{t}$ labor augmenting technology and $L_{t}$ the number of agents. The gross growth rate of labor-augmenting technology is:

$$
g_{t}=x_{t} / x_{t-1}
$$

which is subject to an auto-regressive process:

$g_{t}=\left(1-\rho_{g}\right) \gamma+\rho_{g} g_{t-1}+\varepsilon_{t}^{g}$

where $\rho_{g}$ is the persistence, $\gamma$ is the steady-state of gross growth rate and ${ }^{g g}{ }_{t}$ is a white-noise shock. The aggregate production and profit functions on a per agent basis are: 


$$
\begin{gathered}
y_{t}=f\left(k_{t}, x_{t}\right)=k_{t}^{\alpha} x_{t}^{1-\alpha} \\
\pi t=y t-w t-r t k t
\end{gathered}
$$

where $y_{t}$ is output per capita, $k_{t}$ is capital per agent and $\pi_{t}$ is profit per agent. The labor market is perfectly competitive. A firm that is matched with an agent deploys capital that is equal to the agent's savings $a_{t}$. However, since only $p_{t}$ firms are matched, the aggregate capital on a per agent basis is only a fraction $p_{t}$ of the agent's assets:

$$
k t=p t a t
$$

Note that Financial Efficiency $p_{t}$ enters the production function in a similar manner to capital utilization (Greenwood et al. 1988). I view Financial Efficiency as the long term trend and capital utilization as the cycles about the trend. Accordingly, the identification of Financial Efficiency is further discussed in the estimation section. Finally, the matching probability $p_{t}$ is subject to an auto-regressive process:

$p_{t}=\left(1-\rho_{p}\right) \bar{p}+\rho_{p} p_{t-1} \varepsilon_{t}^{p}$

where $\bar{p}$ is its steady-state, $\rho_{p}$, its persistence and $\varepsilon_{t}^{p}$ is a white-noise shock. I choose to model $g_{t}$ and $p_{t}$ stochastically in order estimate their trajectories rather than their averages $\bar{p}$ and $\gamma$. This is especially important for Financial Efficiency $p_{t}$, which is the subject of this paper. However, estimating the trajectory of the Financial Efficiency component of TFP requires its differentiation from changes to technological growth $g_{t}$, which is therefore modeled stochastically as well. Steady-states are required for all variables of the model, however, the estimation will show that $\bar{p}$ plays only a small role due to a high persistence $\rho_{p}$.

\section{Equilibrium}

I define the model's stationary variables as follows: $\tilde{k}_{t}=k_{t} / x_{t}, \tilde{a}_{t}=a_{t} / x_{t}, \tilde{y}_{t}=y_{t} / x_{t}, \widetilde{w}_{t}=$ $w_{t} / x_{t}, \tilde{c}_{t}=c_{t} / x_{t}$. The labor market is competitive and therefore the equilibrium wage equals the marginal product of labor:

$\widetilde{w}_{t}=(1-\alpha) \tilde{y}_{t}$

where the production function is:

$\tilde{y}_{t}=\left(p_{t} \tilde{a}_{t}\right)^{\alpha}$

Consequently, firm surplus over wages equals:

$$
\tilde{y}_{t}-\widetilde{w}_{t}=\alpha \tilde{y}_{t}
$$

Matched agents make a take-it or leave-it offer for the full surplus and therefore the capital income equals:

$$
r_{t} \tilde{k}_{t}=\alpha \tilde{y}_{t}
$$

where $r_{t}$ is the marginal product of capital. Any other bargaining solution may be assumed provided that the firms distribute their profits to the agents. Consequently, the marginal product of capital equals:

$r_{t}=\alpha \tilde{k}_{t}^{\alpha-1}=\alpha p_{t}^{\alpha-1} \tilde{a}_{t}^{\alpha-1}$

Note that the return on agents' assets is an adjusted marginal product of capital $p_{t} r_{t}$. The first order conditions of the agents produce the Euler equation and the budget constraint: 
$E_{t}\left(g_{t+1} \frac{\tilde{c}_{t+1}}{\tilde{c}_{t}}\right)=\beta\left[1+E_{t}\left(p_{t+1} r_{t+1}\right)\right]$

$E_{t}\left(g_{t+1} \tilde{a}_{t+1}\right)=\left(1+p_{t} r_{t}\right) \tilde{a}_{t}+\widetilde{w}_{t}-\tilde{c}_{t}$

The laws of motion for technology growth of equation (1) and Financial Efficiency of equation (2) close the model. Equations (1)-(7) characterize the model.

\section{Steady-State}

The economy described above has a non-stochastic steady-state, in which the equilibrium conditions simplify to:

$$
\begin{aligned}
& w=(1-\alpha) \bar{p}^{\alpha} a^{\alpha} \\
& r=\alpha \bar{p}^{\alpha-1} a^{\alpha-1} \\
& \gamma=\beta(1+\bar{p} r) \\
& c=w+a(1+\bar{p} r-\gamma)
\end{aligned}
$$

\section{Financial Development}

I consider an increase in Financial Efficiency $\bar{p}$ to be synonymous with Financial Development. Financial Development, expressed as a gross growth rate $\tau$ of Financial Efficiency is predicted by the model to lead to stationary output per capita growth through transition from one balanced growth path to another. The stationary output per capita from equations (9), (10) and (4) is:

$$
\tilde{y}=\left(\frac{\alpha \beta \bar{p}}{\gamma-\beta}\right)^{\frac{\alpha}{1-\alpha}}
$$

Hence, a gross growth rate $\tau$ in Financial Efficiency leads to a gross growth rate in stationary output per capita in the new balanced growth path:

$$
\tau \frac{\alpha}{1-\alpha}
$$

With a capital share of income $\alpha=1 / 2$, the gross growth rate of Financial Efficiency equals the gross growth rate in stationary output per capita. If the capital share is higher, it amplifies Financial Development's effect on stationary output per capita growth and if it is lower it dampens Financial Development's effect on output per capita growth.

\section{Financial Integration}

So far I have focused on the description of the closed economy, which will be analyzed in the next section. I now address Financial Integration that will be analyzed in the fourth section. I consider a small home economy in steady-state as described above, with low Financial Efficiency $p$. A foreign large economy in steady-state as described above but with all variables marked by stars has a high Financial Efficiency $p^{*}$, such that:

$$
p^{*}>p
$$

The two economies use the same production technology. 


\section{CLOSED ECONOMY}

\section{Calibration}

I calibrate the following parameters of the model according to KPR (King et al. 1988, King and Rebelo 1999) on an annual basis:

\begin{tabular}{ccccc}
$\alpha$ & $\beta$ & $\gamma$ & $\rho_{g}$ & $\rho_{p}$ \\
\hline 0.33 & 0.949 & 1.009 & 0.3 & 0.9
\end{tabular}

where $\alpha$ is the capital share of income, $\beta$ is an annual discount factor and $\gamma$ is the annual gross growth rate in labor augmenting technology. For persistence of labor augmenting technology growth I use 0.3 and for the persistence of Financial Efficiency I use 0.9 based on the results of the estimation in the next section. All the parameters are estimated in the section 5.

\section{Welfare Consequences}

Using the steady state conditions I compute steady-state lifetime utility from consumption as a function of Financial Efficiency. The lifetime utility from consumption in steady state is:

$W=\frac{\ln c}{1-\beta \gamma \mid}$

Using equations (8), (9), (10) and (11) in (12), the closed form lifetime welfare is:

$W=\frac{\ln \left[(1-\alpha) \bar{p}^{\alpha}\left(\frac{\alpha \bar{p}^{\alpha} \beta}{\gamma-\beta}\right)^{\frac{\alpha}{1-\alpha}}+\left(\frac{\alpha \bar{p}^{\alpha} \beta}{\gamma-\beta}\right)^{\frac{1}{1-\alpha}} \frac{\gamma(1-\beta)}{\beta}\right]}{1-\beta \gamma}$

Figure 1 presents welfare $W$ as a function of Financial Efficiency $p^{-}$. As expected, lifetime welfare is strictly increasing in the Financial Efficiency. It demonstrates that the economic impact of Financial Efficiency on economic welfare is disproportionally large in less financially developed economies.

FIGURE 1

WELFARE

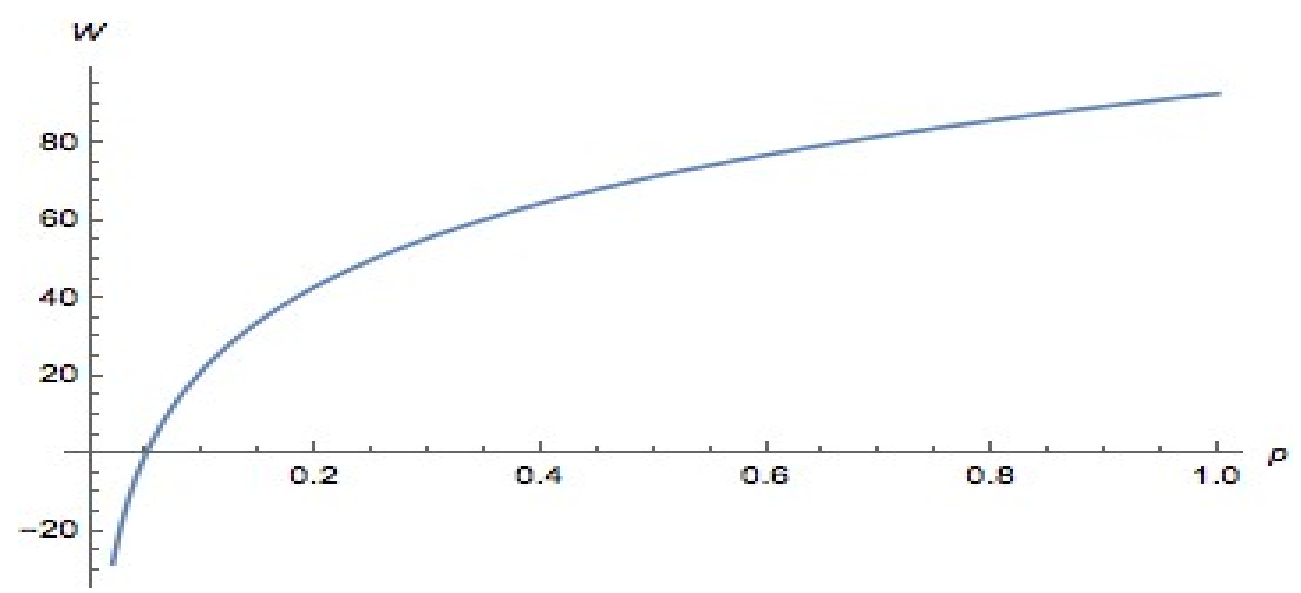

Notes: This figure presents the welfare as a function of Financial Efficiency. It demonstrates that the economic impact of Financial Efficiency on economic welfare is disproportionally large in less financially developed economies. 


\section{Transitional Dynamics}

Following King and Rebello (1993) I check whether Financial Efficiency affects the convergence of the economy to its steady-state balanced growth path. The benchmark economy is the textbook Real Business Cycle (KPR) model economy with 100\% Financial Efficiency and the second economy has a Financial Efficiency of 50\%. The two economies start the simulation with assets that produce stationary output per capita $\tilde{y}_{0}$ such that $\frac{\tilde{y}_{S S}}{\tilde{y}_{0}}=\sqrt{7}$ where $\tilde{y}_{s S}$ is the steady-state of stationary output per capita. Figure 2 shows the convergence of the two economies to their respective steady-state balanced growth paths. The two economies have different balanced growth steady-states but they converge to their balanced growth paths at the same rate. Hence, Financial Efficiency does not affect the rate of convergence.

FIGURE 2

CONVERGENCE
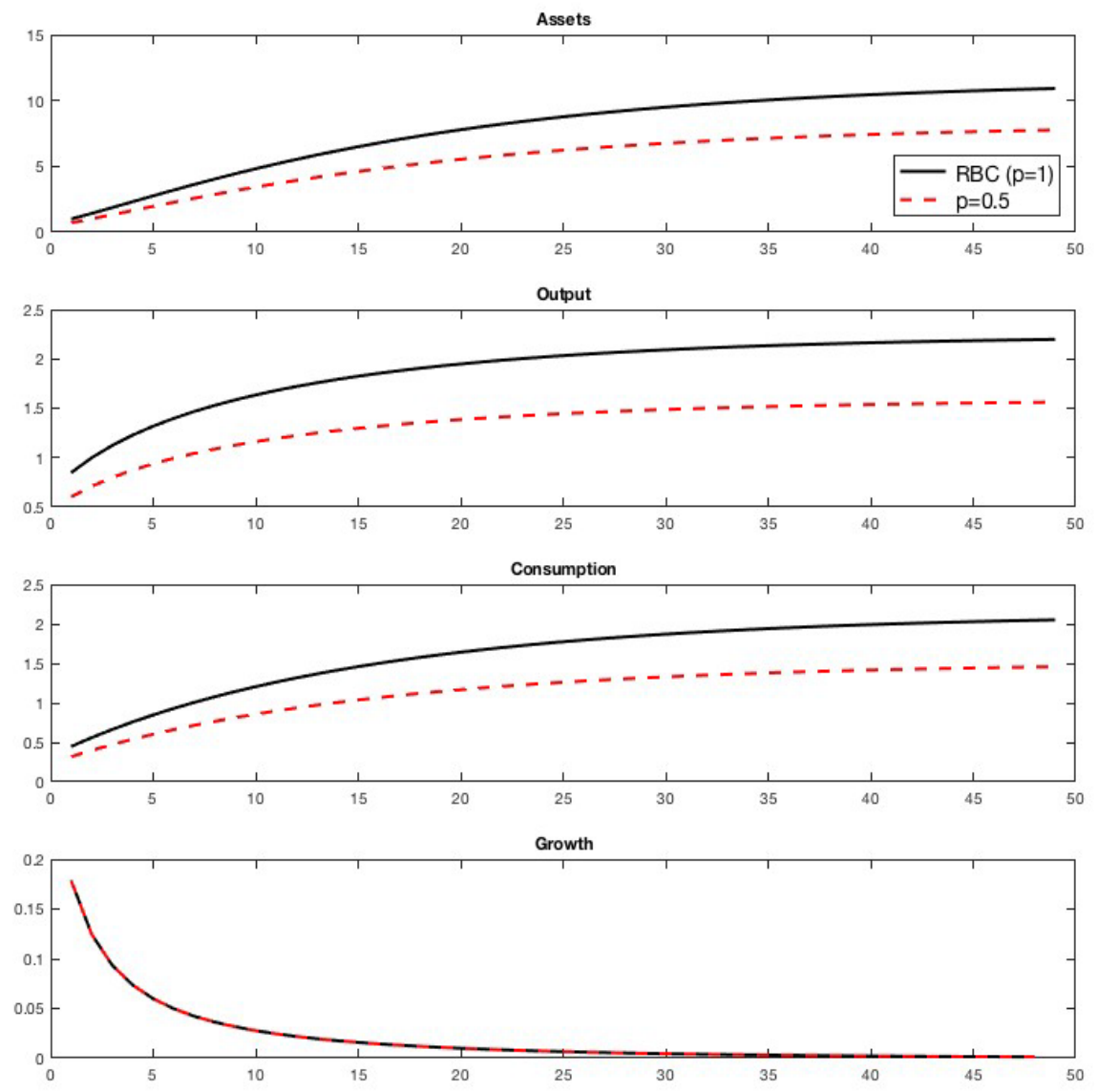

Note: This figure shows the convergence of two economies with different Financial Efficiencies to their respective balanced growth paths.

The second experiment that I conduct is one of Financial Development where an economy increases its Financial Efficiency from 50\% to $80 \%$ within one year leading to a Financial Development of $\tau=1.6$. Figure 3 shows the convergence of key model variables following this Financial Development event. Output per capita increases immediately by $\tau^{\alpha}=1.169$ due to the contribution of Financial Development to TFP. However, assets continue to accumulate over 50 years and lead to an overall gross output per capita growth of $\tau^{\frac{\alpha}{1-\alpha}}=1.265$. Consequently, consumption also converges to its new balanced growth level over 50 years. 


\section{FIGURE 3}

\section{FINANCIAL DEVELOPMENT}
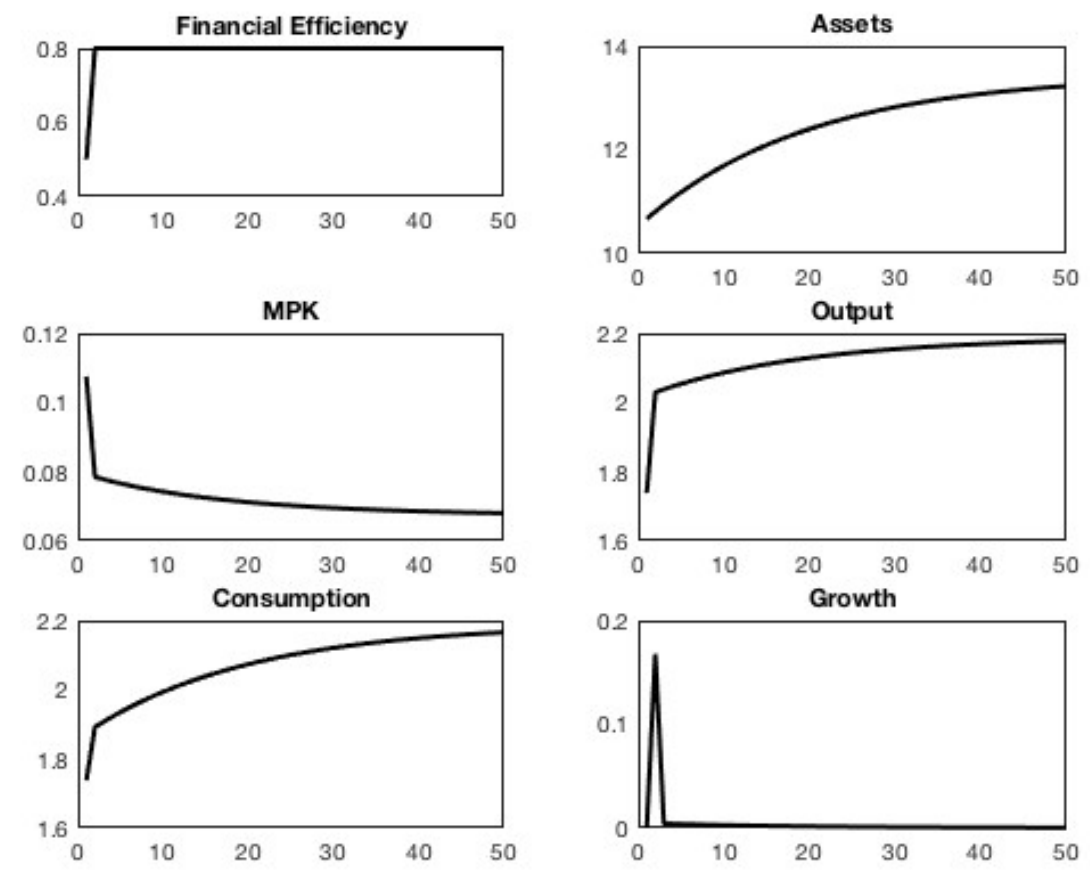

Note: This figure shows the response of key model variables to a permanent Financial Development event that increases Financial Efficiency from 50\% to 80\% within one year.

\section{LUCAS PUZZLE}

Financially integrating the home and foreign economies, previously described, to capital flows does not affect the large economy but on the other hand, due to the flow of FDI capital, the small economy's return on assets is equalized to that of the large economy. As previously noted, the return on agents' assets $p_{t} r_{t}$ is an adjusted marginal product of capital $r_{t}$. Hence, after capital is allowed to flow from the rich to the poor economy the return on assets in the two economies equalize:

$p^{*} r^{*}=p r$

Based on equation (5), the stationary capital per capita in both countries must obey:

$$
p^{*} r^{*}=\alpha p^{*} k^{*(\alpha-1)}=\alpha p k^{\alpha-1}=p r
$$

The resulting stationary capital per capita ratio is proportional to the Financial Efficiency ratio:

$k^{*} / k_{F I}=\left(\frac{p^{*}}{p}\right)^{\frac{1}{1-\alpha}}$

where $k^{*} / k_{F I}$ is the financially integrated economies stationary capital per capita ratio. Since $\left(\frac{p^{*}}{p}\right)^{\frac{1}{1-\alpha}}>1$, the stationary capital per capita in the home country remains lower than in the foreign country $k<k^{*}$ due to the lower Financial Efficiency in the home country $p<p^{*}$. In order to check if any capital flows from one economy to the other, I compare the stationary capital per capita ratio of the closed economies to the 
stationary capital per capita ratio of the financially integrated economies. The closed economy steady-state stationary capital per capita from equations (9) and (10) is:

$k=\left(\frac{\alpha \beta p}{\gamma-\beta}\right)^{\frac{1}{1-\alpha}}$

I previously assumed that both countries use the same production technology $\left(\alpha, \gamma, x_{t}\right)$. Assuming that the discount factor $\beta$ is shared by the two economies then the stationary capital per capita ratio of the closed economies $\tilde{k}^{*} / \tilde{k}_{C E}$ is identical to the stationary capital per capita ratio in the financially integrated economies of equation 15 :

$k^{*} / k_{F I}=k^{*} / k_{C E}=\left(\frac{p^{*}}{p}\right)^{\frac{1}{1-\alpha}}$

where $k^{*} / k_{C E}$ is the stationary capital per capita ratio of the closed economies. Hence, there is no flow of capital from the rich country to the poor one upon the financial integration of the economies. Moreover, based on equations (17) and (5), the Financial Efficiency adjusted marginal product of capital $p r$ in the two closed economies are equal before financial integration, in line with Caselli and Feyrer (2007). Relaxing the assumption of equal discount rates between the two economies is beyond the scope of this paper but the discount rate for India is estimated in the fifth section.

The model provides the construct of Financial Efficiency as an explanation for why the capital per capita in different closed economies is different to begin with, why the adjusted marginal product of capital is equal in different closed economies despite different capital per capita, and why there is no flow of capital from the rich to the poor economy once the economies financially integrate. On the other hand, the model predicts that a country, which experiences Financial Development $\uparrow p$, experiences an inflow of FDI capital from foreign countries and a rise in stationary capital per capita. Figure 4 compares the transition dynamics of a closed economy to that of a financially integrated economy following Financial Development of $\tau=$ 1.6 from a Financial Efficiency of $50 \%$ to $80 \%$. The financially integrated economy converges immediately to its balanced growth path due to foreign assets inflow. Similar to the closed economy it experiences output per capita growth in the first year of Financial Development due to the contribution of Financial Efficiency to TFP. While the closed economy continues to experience convergence for many years after the Financial Development event, the financially integrated economy experiences accelerated convergence for only one period due to foreign assets inflow. Consumption in the closed economy is lower in the first 15 years due to lower capital per capita. However, thereafter the domestic assets in the closed economy are larger than those in financially integrated economy, which partially relies on foreign assets. Consequently, total income in the closed economy after the 15 th year is higher than in the financially integrated economy due to higher capital income. Less early consumption in the closed economy allows for more consumption eventually. 
FIGURE 4

\section{FINANCIAL DEVELOPMENT WITH FINANCIAL INTEGRATION}
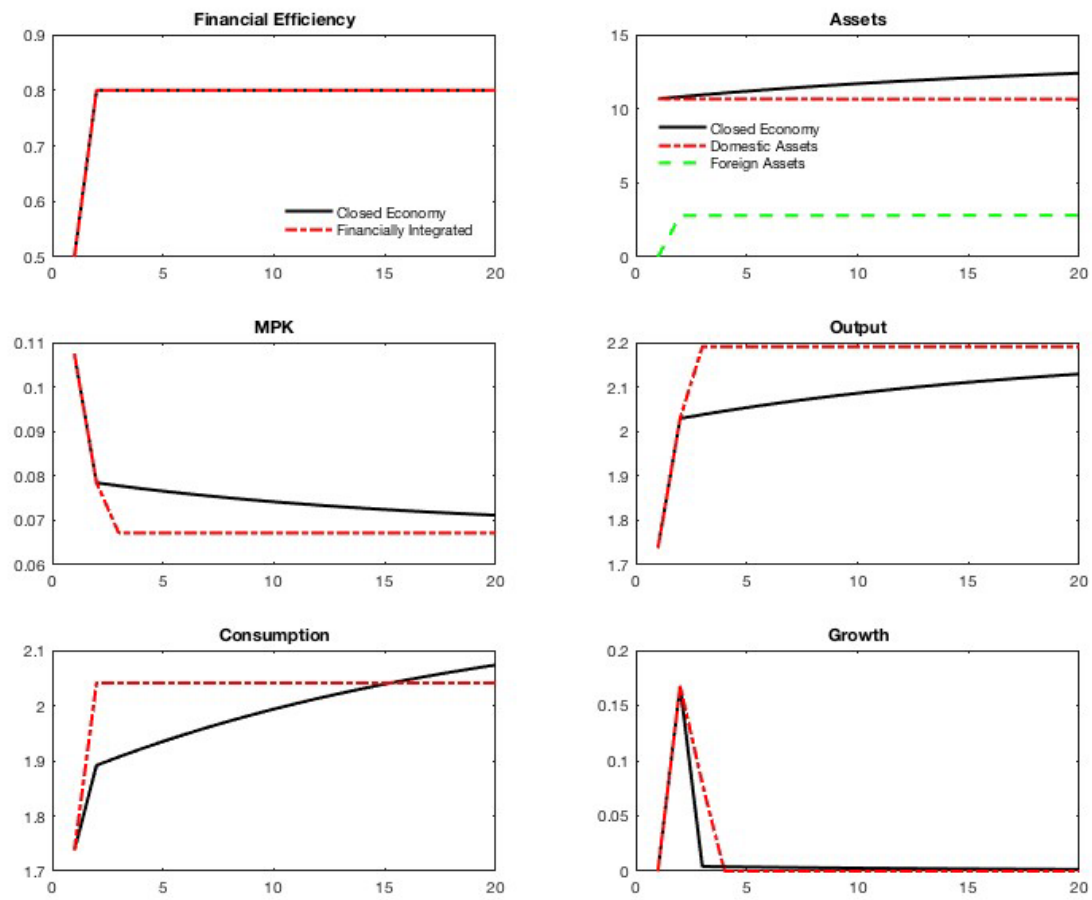

Note: This figure shows the transition of key model variables following a permanent Financial Development event that increases Financial Efficiency from 0.5 to 0.8 within one year in a closed economy vs. a financially integrated economy. The financially integrated economy converges immediately to its balanced growth path due to foreign assets inflow.

To make the analysis more complete I perform a similar analysis for the case of a less developed home economy, both financially and technologically, that experiences a temporary faster technology growth than the foreign developed economy as it is catching up to it technology. Hence $p<p^{*}, x_{t}<x_{t}^{*}$, but $\gamma>\gamma^{*}$. Since $\tilde{k}=k_{t} / x_{t}$, the financially integrated economy's capital per capita ratio of equation (15) may be rewritten as:

$$
k^{*} / k_{F I}=\frac{x_{t}^{*}}{x_{t}}\left(\frac{p^{*}}{p}\right)^{\frac{1}{1-\alpha}}
$$

The closed economies capital per capita ratio based on equation (16) can be rewritten as:

$$
k^{*} / k_{C E}=\frac{x_{t}^{*}}{x_{t}}\left(\frac{\alpha \beta p^{*}}{\alpha \beta p}\right)^{\frac{1}{1-\alpha}}\left(\frac{\gamma-\beta}{\gamma^{*}-\beta}\right)^{\frac{1}{1-\alpha}}
$$

which simplifies to:

$k^{*} / k_{C E}=k^{*} / k_{F I}\left(\frac{\gamma-\beta}{\gamma^{*}-\beta}\right)^{\frac{1}{1-\alpha}}$

Since $\gamma>\gamma^{*}, \frac{\gamma-\beta}{\gamma^{*}-\beta}>1$, hence the capital per capita ratio is larger in the closed economy than in the financially integrated economy: 


\section{$k * / k C E>k * / k F I$}

Therefore, higher technology growth in the less developed economy will result in FDI capital flow out of the developed economy upon financial integration.

In summary, a financially underdeveloped economy is predicted to benefit from financial integration due to FDI capital inflow only if it experiences faster technological growth than the developed economy, or if it experiences faster Financial Development than the developed economy. This analysis helps settle the contention between Rodrik and Subramanian (2009) and Henry (2007) regarding the benefits and pitfalls of financial globalization by identifying the conditions for when financial integration is beneficial for a developing economy.

\section{ESTIMATION}

In this section I fit the model to the data of India. I estimate the parameters of the model as well as the temporal evolution of Financial Efficiency $p_{t}$.

I use Dynare in order to linearize the model around its steady-state, convert it to a reduced form and perform Bayesian estimation with 5 blocks of Metropolis-Hastings simulations of 300,000 iterations. Timeseries' estimations are usually performed using State-Space Bayesian methods since they allow the estimation of unobserved state variables such as Financial Efficiency $p_{t}$.

\section{Identification}

I use two observable variables: output per capita $y_{t}$, and consumption per worker $c_{t}$. I use two structural shocks, a white noise technology growth shock $\varepsilon_{t}^{g}$ and a Financial Efficiency white noise shock $\varepsilon_{t}^{p}$. The estimation maximizes the fit of the model's observable variables to the data by choosing the parameters and the evolution of the unobserved variables, such as Financial Efficiency.

The evolution of capital per capita is identified by the Kalman Smoother algorithm based on data on output per capita according to the production function: $y_{t}=k_{t}^{\alpha}$. The evolution of assets is identified based on data on output per capita and consumption per capita according to equation (7), which may be re-written as: $a_{t+1}-a_{t}=y_{t}-c_{t}$. Once the evolutions of both capital and assets are identified, the evolution of Financial Efficiency is identified via the relationship in the model between assets and capital: $k_{t}=p_{t} a_{t}$.

Table 1 summarizes the prior information that I use in these estimations. I use the KPR based calibration from section 3 as the prior for the first three parameters. For the other parameters I use a non-informative prior, which allows the data to determine their posterior distributions.

TABLE 1

PRIORS

\begin{tabular}{|c||c||c|c|}
\hline Parameter & Probability Density & Mean & Standard Deviation \\
\hline \hline$\alpha$ & Beta & 0.33 & 0.05 \\
\hline$\beta$ & Beta & 0.949 & 0.002 \\
\hline$\gamma$ & Normal & 1.009 & 0.001 \\
\hline \hline$\rho^{-}$ & Beta & 0.5 & 0.1 \\
\hline \hline$\rho_{g}$ & Normal & 0.5 & 0.1 \\
\hline \hline
\end{tabular}

Notes: This table reports the prior means and standard deviations for the parameters of the model. 


\section{Data}

I use annual data on Real GDP (World Bank) and Real Total Consumption (World Bank) divided by Number of Persons Engaged (FRED) from 1960 to 2017. The data is converted to logs and then into first differences in order to avoid co-integration while preserving information on growth. By using annual data I aim to capture the longer term trend of Financial Efficiency while abstracting from the short term cycle capital utilization.

\section{Results}

Figure 5 presents the prior and posterior probability densities of the estimated parameters of the model. Table 2 presents the prior vs. posterior means and standard deviations. The posterior mode of the capital share of income, $\alpha$, is estimated by the model to be 0.3725 for India. This estimate is higher than the KPR based calibration, which is consistent with the increase in the capital share of income as estimated by Karabarbounis and Neiman (2014). The mode for the discount factor, $\beta$, is estimated to be 0.9843 . Labor augmenting technology gross growth rate's mode in steady-state, $\gamma$, is estimated to be 1.0211 , which is much higher than the KPR based prior but consistent with a developing economy. Financial Efficiency's mode in steady-state, $p^{-}$, is estimated to be 0.5195 . However, steady-state Financial Efficiency is only weakly identified since the model puts much weight on the persistence of its law of motion $\rho_{p}$ rather than on its average. Consequently, the steady-state plays only a small role in determining Financial Efficiency $p_{t}$. The modes of the persistence parameters $\rho_{p}$ and $\rho_{g}$, are 0.9734 for $\rho_{p}$ and 0.2987 for $\rho_{g}$. These estimates are data driven since their prior is non-informative. Note that these persistence parameters are not for TFP but for technology growth and Financial Efficiency. Also note that the persistence of Financial Efficiency is high because the variable is in levels while the persistence of technology growth is low since the variable is a growth rate.

FIGURE 5

\section{BAYESIAN ESTIMATION OF PARAMETERS FOR INDIA}
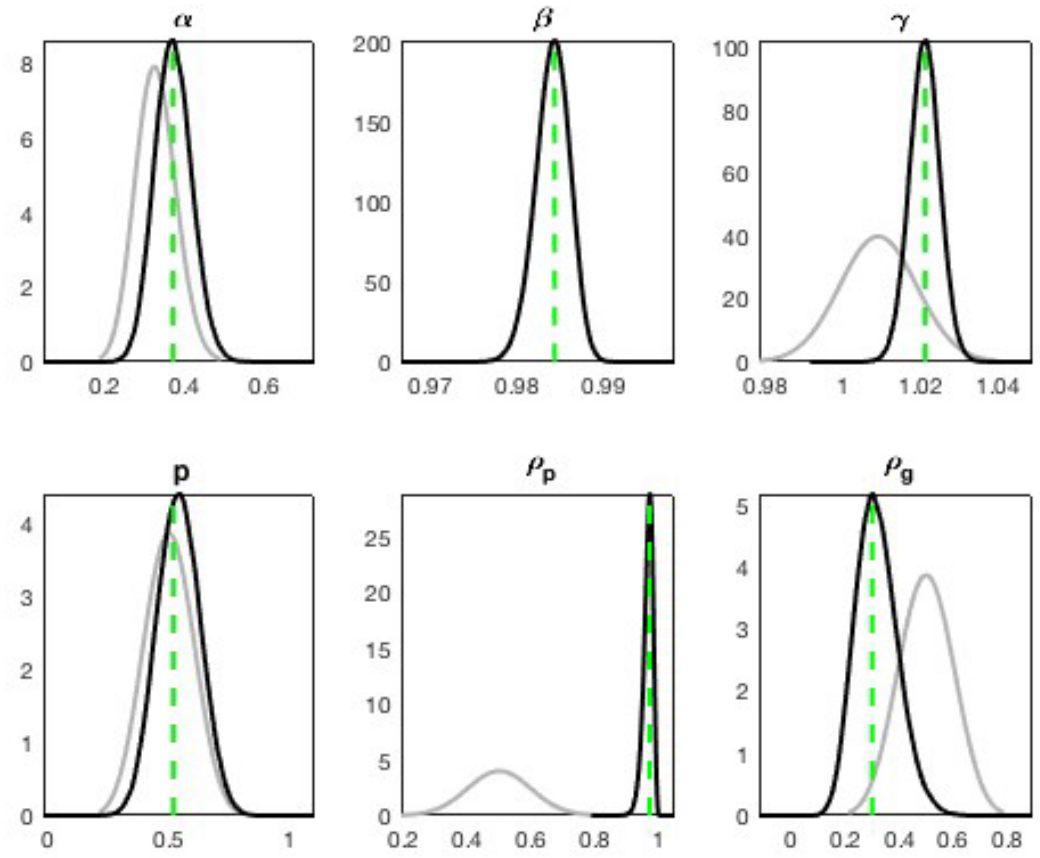

Notes: This figure reports the prior (gray) and posterior (black) densities for the parameters of the model when fitted to India's economic data. 
FIGURE 6

\section{SMOOTHED TFP COMPONENTS}
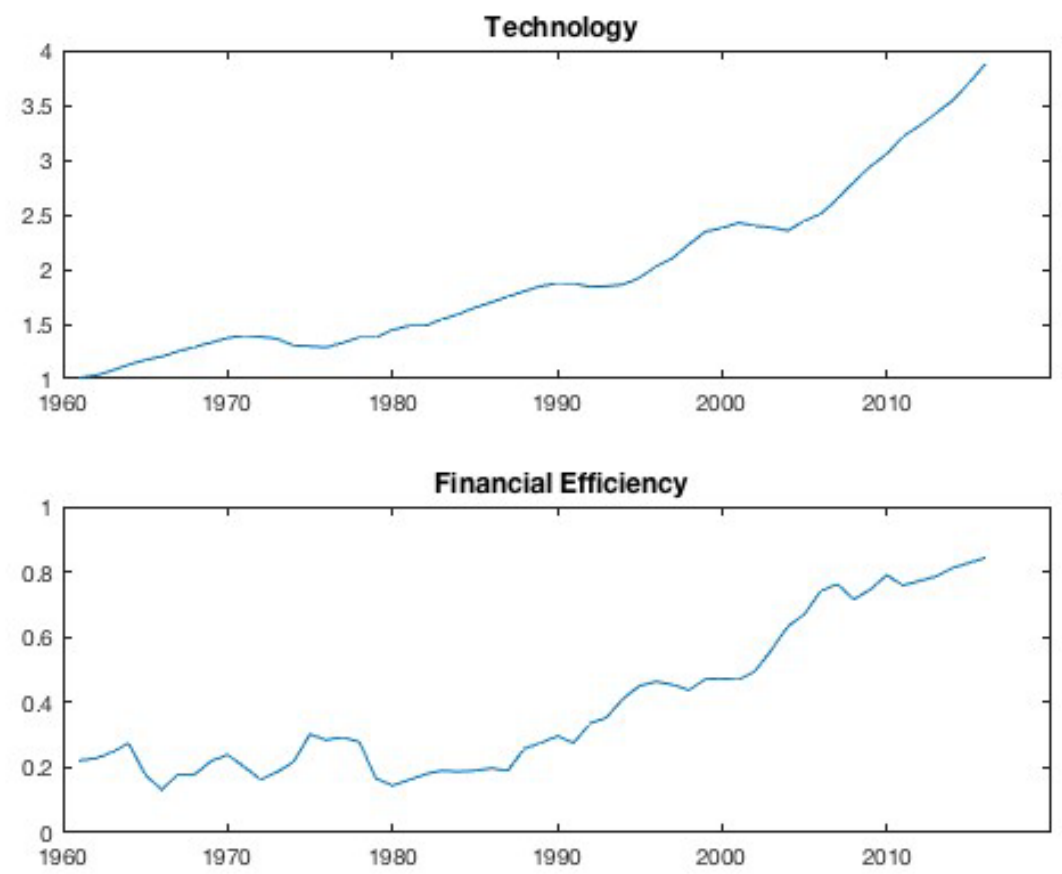

Notes: This figure compares the estimated Kalman Smoother evolution of Technology and Financial Efficiency over time. Technology is normalized to unity at the beginning of the sample.

TABLE 2

PRIORS VS. POSTERIORS FOR INDIA

\begin{tabular}{|c||c||c|c||c||c|}
\hline Parameter & $\begin{array}{c}\text { Probability } \\
\text { Density }\end{array}$ & $\begin{array}{c}\text { Prior } \\
\text { Mean }\end{array}$ & $\begin{array}{c}\text { Posterior } \\
\text { Mean }\end{array}$ & Prior Std & $\begin{array}{c}\text { Posterior } \\
\text { Std }\end{array}$ \\
\hline \hline$\alpha$ & Beta & 0.33 & 0.3724 & 0.05 & 0.0456 \\
\hline \hline$\beta$ & Beta & 0.949 & 0.984 & 0.002 & 0.002 \\
\hline \hline$p^{-}$ & Normal & 1.009 & 1.021 & 0.01 & 0.0039 \\
\hline \hline$\rho_{p}$ & Beta & 0.5 & 0.5392 & 0.1 & 0.0878 \\
\hline \hline$\rho_{g}$ & Beta & 0.5 & 0.9685 & 0.1 & 0.0152 \\
\hline
\end{tabular}

Notes: This table compares the prior and posterior means and standard deviations for the parameters of the model fitted to India's economic data.

Figure 6 depicts the temporal evolution of technology and Financial Efficiency that are generated by the Kalman Smoother algorithm where technology is the commutative product of technology growth and is normalized to unity at the beginning of the sample. India's Financial Efficiency did not change much until the early 1990's. Thereafter, it increased from around 0.297 to 0.844 , a Financial Development of $\tau=$ 2.84. This increase makes it difficult to interpret $p_{t}$ as capital utilization and supports the interpretation of $p_{t}$ as Financial Efficiency. There were two bouts of sharp Financial Development, the first in the early 1990 's and the second in the early to mid 2000's. In addition, the technology panel of figure 6 shows that 
India experienced accelerated technological growth since the mid 1990's and even more so since the mid 2000's. It appears that periods of Financial Development, such as the early 1990's and early 2000's, are followed by periods of accelerated technology growth, such as the mid to late 1990's and the mid 2000's and on.

The theoretical model of this paper predicts that India's Financial Development would lead to an increase in capital per worker. Figure 7 shows the stationary real capital per worker during the sample period, which is obtained by dividing Real Capital Stock by the Number of Persons Engaged as well as by technology obtained through the estimation. Data on capital is not used in the estimation and therefore it may be used to test the predictions of the theoretical model in light of its empirical results. The stationary capital per worker grew by more than 30\% between 1960 and 1972 without any substantial changes in Financial Efficiency or technology growth rate, hence it may only be attributed to balanced growth path convergence. A second and third bouts of growth in stationary capital per worker occurred between 1990 and 1996 and between 1998 and 2012, which were periods of Financial Development and acceleration in technology growth. From equations (9) and (10), stationary capital per worker in steady-state is:

$$
k=\left(\frac{\alpha \beta \bar{p}}{\gamma-\beta}\right)^{\frac{1}{1-\alpha}}
$$

A Financial Development of $\tau=2.84$ is predicted by the model to lead to stationary capital per worker growth of $\tau^{\frac{1}{1-\alpha}}=4.5$. However, technology growth acceleration should lead to a decline of stationary capital per worker by the multiplier:

$$
\left(\frac{\gamma_{0}-\beta}{\gamma_{1}-\beta}\right)^{\frac{1}{1-\alpha}}
$$

The average estimated technology growth rate from 1960 to 1993 was 1.019, from 1994 to 2003 it was 1.024 and from 2004 to 2015 it was 1.043 . Hence, technology growth acceleration is predicted by the model to reduce stationary capital per worker by $20 \%$ between 1994 and 2003, by further $45 \%$ between 2004 and 2015 and overall by $66 \%$ between 1994 to 2015 . Consequently, the model's theoretical prediction based on the results of the estimation is that the stationary capital per worker would increase 2 fold between 1990 and 2015. The actual stationary capital per worker grew 1.58 fold, $20 \%$ less than the model's prediction. During the early 1990 it appears as if stationary capital per worker did not increase despite substantial Financial Development but in fact, an increase in technology growth rate was offsetting the effect of Financial Development. Financial Development did coincide with stationary capital per worker increase despite an increase in technology growth rate.

In addition, both Financial Development and accelerated technology growth are predicted by the model to lead to an inflow of FDI capital. Figure 8 shows the stationary FDI capital inflow per worker obtained by dividing FDI net inflows from the World Bank by the Number of Persons Engaged as well as by technology obtained through the estimation. Stationary FDI capital per worker inflow began to grow in the early 1990's along with Financial Efficiency and before the increase in technology growth rate that occurred in the mid 1990's. Between 2000 and 2005, another bout of stationary FDI capital per worker inflow growth occurred along with Financial Efficiency and before the increase in technology growth rate that occurred in the mid 2000's. From 2005 to 2008 stationary FDI capital per worker inflow grew six fold, which coincided with both Financial Development and an increase in technology growth rate. The fluctuations of stationary FDI capital per worker inflow post 2008 track well with those in Financial Efficiency. These independent facts confirm the predictions of the theoretical model that an increase in Financial Efficiency or technology growth rate lead to stationary FDI capital per worker inflow growth. In addition, they confirm the conditions for when financial integration is beneficial for a developing economy, helping to resolve the 
contention between Rodrik and Subramanian (2009) and Henry (2007) regarding the benefits and pitfalls of financial globalization.

FIGURE 7

STATIONARY CAPITAL PER WORKER

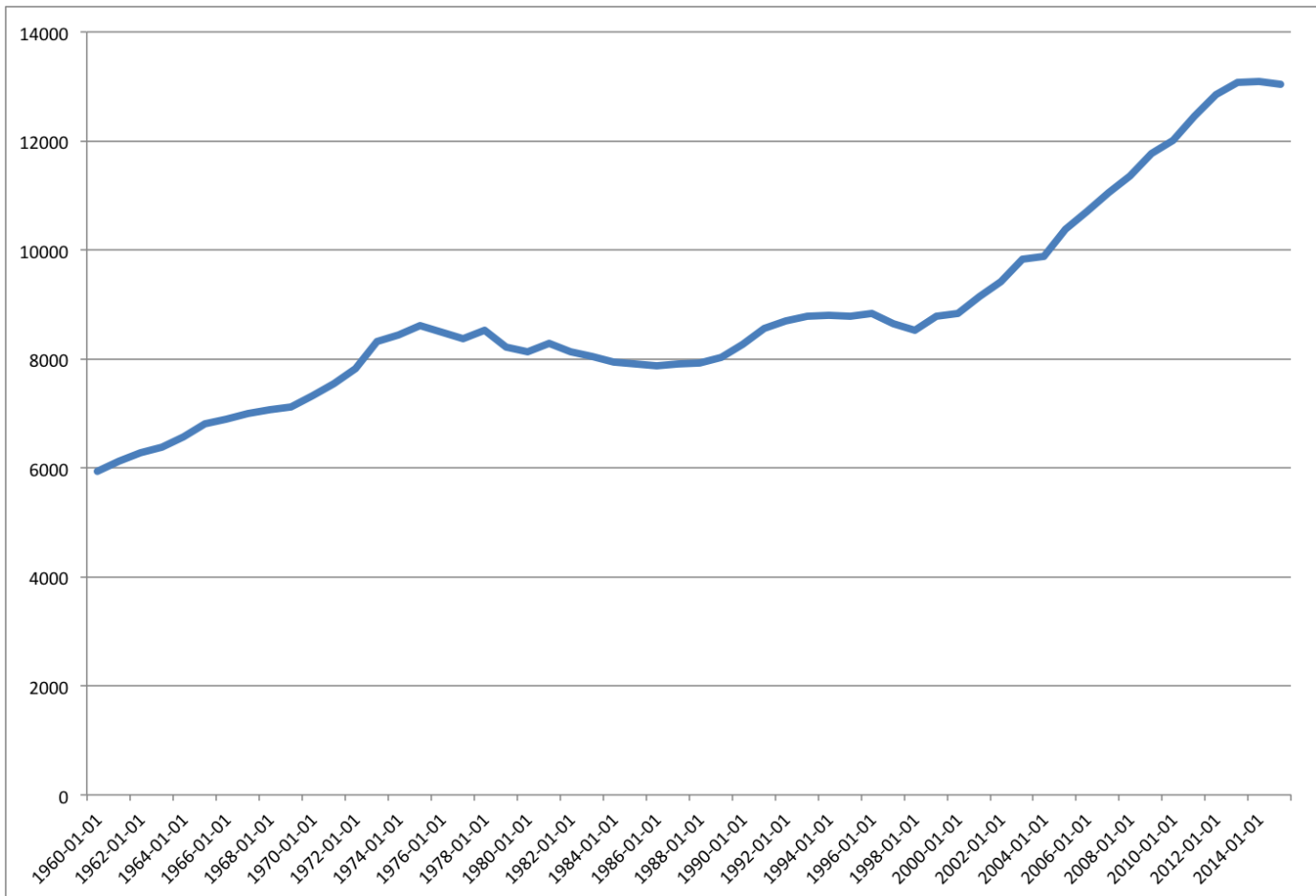

Source: Real Capital Stock divided by Number of Persons Engaged as well as by technology obtained through the estimation.

\section{CONCLUSIONS}

I presented a model that provides a theoretical solution to the Lucas Puzzle and allows the estimation of the trajectory of Financial Efficiency, unifying the theoretical with the empirical. The model distinguishes between two components of TFP growth, the first is labor augmenting technology growth and the second is capital augmenting Financial Development. The evolution of the financial system, in this paper, contributes to economic growth in two ways. First, it contributes to TFP directly and immediately. Second, it changes the steady-state of the model, which over time, leads to growth in capital per capita and output per capita until the new steady-state is reached. 
FIGURE 8

FOREIGN DIRECT INVESTMENT IN INDIA

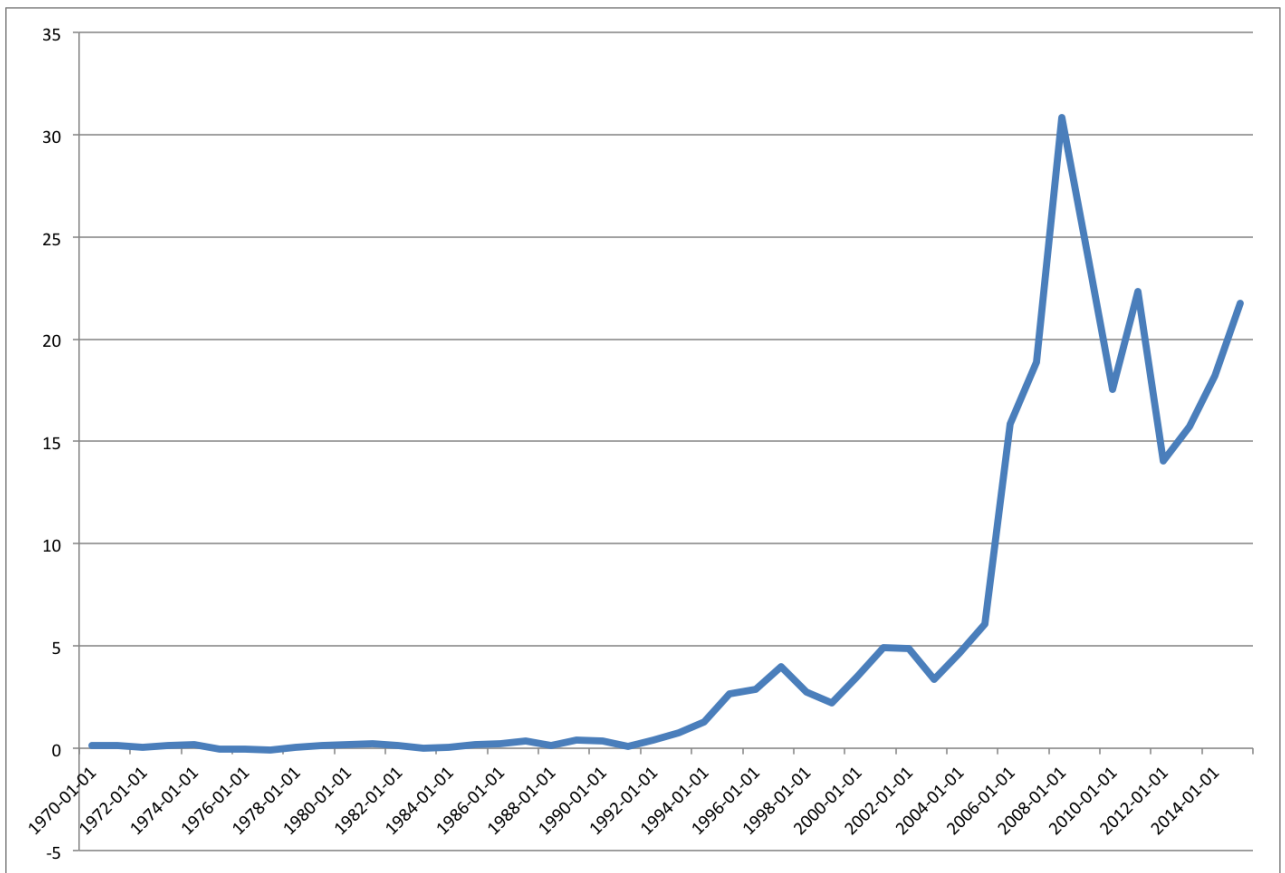

Source: World Bank Databank, divided by Number of Persons Engaged as well as by technology obtained through the estimation.

Notes: This figure shows that Foreign Direct Investment in India increased ten fold following a period of accelerated Financial Development estimated by the model, confirming the model's prediction.

Financial integration in the model leads to a ratio of capital per capita of two countries, which is proportional to their Financial Efficiencies ratio. A financially underdeveloped economy is predicted to benefit from financial integration through FDI capital inflow growth only if it experiences faster technological growth, or faster Financial Development than the developed economy. This finding may help resolve the contention between Rodrik and Subramanian (2009) and Henry (2007) regarding financial globalization by providing conditions for when financial integration is beneficial for an underdeveloped economy.

The estimated increases in India's Financial Efficiency in the early 1990's and 2000's provide tests for the theoretical prediction mentioned above and its congruence with the empirical part of the model. I provided external validation showing that stationary FDI capital per worker inflow grew six fold and that stationary capital per worker grew only $20 \%$ less than the model's theoretical prediction during the sample period.

The limitation of the model is that Financial Efficiency is a "catch-all" variable that does not provide insight into the mechanisms that change the relationship between accumulated savings and productive capital. Further research could identify the components of Financial Efficiency and identify their relative contribution to Financial Development. A broad spectrum of work mentioned by Levine (2005) suggests that political, legal, cultural, and even geographical factors influence the financial system. 


\section{REFERENCES}

Angeletos, G-M., \& Panous, V. (2011, May). Financial integration, entrepreneurial risk and global dynamics. Journal of Economic Theory, 146(3), 863-896.

Caselli, F., \& Feyrer, J. (2007). The Marginal Product of Capital. Quarterly Journal of Economics, p.34.

Easterly, W., \& Levine, R. (2001). It's Not Factor Accumulation: Stylized Facts and Growth Models. The World Bank Economic Review.

Goldsmith, R.W. (1969). Financial structure and development. Yale University Press, New Haven. OCLC:12366.

Gourinchas, P-O., \& Jeanne, O. (2013, October). Capital Flows to Developing Countries: The Allocation Puzzle. The Review of Economic Studies, 80(4), 1484-1515.

Greenwood, J., Hercowitz, Z., \& Huffman, G.W. (1988). Investment, Capacity Utilization, and the Real Business Cycle. The American Economic Review, 78(3), 402-417. Publisher: American Economic Association.

Henry, P.B. (2003, May). Capital-Account Liberalization, the Cost of Capital, and Economic Growth. American Economic Review, 93(2), 91-96.

Karabarbounis, L., \& Neiman, B. (2014, February). The Global Decline of the Labor Share. Quarterly Journal of Economics, $129(1)$.

King, R.G., \& Levine, R. (1993, August). Finance and Growth: Schumpeter Might Be Right. The Quarterly Journal of Economics, 108(3), 717-737.

King, R.G., \& Rebelo, S.T. (1993). Transitional Dynamics and Economic Growth in the Neoclassical Model. The American Economic Review. Publisher: American Economic Association.

King, R.G., \& Rebelo, S.T. (1999). Resuscitating Real Business Cycles. Handbook of Macroeconomics, $1 \mathrm{~B}$.

King, R.G., Plosser, C.I., \& Rebelo, S.T. (1988, March). Production, growth and business cycles: I. The basic neoclassical model. Journal of Monetary Economics, 21(2), 195-232.

Levine, R. \& Zervos, S. (1998). Stock Markets, Banks, and Economic Growth. The American Economic Review, 88(3), 537-558.

Levine, R. (2005, January). Chapter 12 Finance and Growth: Theory and Evidence. In P. Aghion \& S.N. Durlauf (Eds.), Handbook of Economic Growth (volume 1, pp. 865-934). Elsevier.

Lucas, R. (1990). Why Doesn't Capital Flow from Rich to Poor Countries? American Economic Review, 80(2), 92-96.

Mendoza, E.G., Quadrini, V., \& Ríos-Rull, J-V. (2009, June). Financial Integration, Financial Development, and Global Imbalances. Journal of Political Economy, 117(3), 371-416.

Reinhart, C.M., \& Rogoff, K.S. (2004). Serial Default and the "Paradox" of Rich-to-Poor Capital Flows. American Economic Review, 94(2), 12.

Rodrik, D., \& Subramanian, A. (2009). Why Did Financial Globalization Disappoint? IMF Staff Papers, 56(1), 112-138. Publisher: [Palgrave Macmillan Journals, International Monetary Fund].

Smith, B.D. (2003). Taking Intermediation Seriously. Journal of Money, Credit and Banking, 35(6), $1319-1357$.

University of Groningen and University of California, Davis. (1950, January). Capital Stock at Constant National Prices for India.

University of Groningen and University of California, Davis. (1950, January). Number of Persons Engaged for India.

von Hagen, J., \& Zhang, H. (2014, January). Financial development, international capital flows, and aggregate output. Journal of Development Economics, 106, 66-77.

World Bank national accounts data and OECD National Accounts data files. (2020). Final consumption expenditure (constant lcu) - India.

World Bank national accounts data and OECD National Accounts data files. (2020). Gdp (constant lcu) India. 